\title{
Ascorbic Acid in Skin Health
}

\author{
Soledad Ravetti ${ }^{1}$, Camila Clemente ${ }^{2}$, Sofía Brignone ${ }^{2}$, Lisandro Hergert ${ }^{2}$, Daniel Allemandi ${ }^{3}$ (I) \\ and Santiago Palma ${ }^{3, *}$ \\ 1 Centro de Investigaciones y Transferencia de Villa María-Instituto Académico Pedagógico de Ciencias Humanas, \\ Universidad Nacional de Villa María, Villa María 5900, Córdoba, Argentina; sravetti@unvm.edu.ar \\ 2 Instituto Académico Pedagógico de Ciencias Básicas y Aplicadas, Universidad Nacional de Villa María, \\ Villa María 5900, Córdoba, Argentina; camilaclemente@conicet.gov.ar (C.C.); sbrignone@conicet.gov.ar (S.B.); \\ lhergert@unvm.edu.ar (L.H.) \\ 3 Facultad de Ciencias Químicas, Universidad Nacional de Córdoba. UNITEFA-CONICET, \\ Córdoba 5000, Argentina; dalemand@fcq.unc.edu.ar \\ * Correspondence: sdpalma@unc.edu.ar; Tel.: +54-351-5353865
}

Received: 23 July 2019; Accepted: 18 September 2019; Published: 1 October 2019

check for updates

\begin{abstract}
Ascorbic acid (vitamin C) is a water-soluble vitamin and a recognized antioxidant drug that is used topically in dermatology to treat and prevent the changes associated with photoaging, as well as for the treatment of hyperpigmentation. Ascorbic acid has neutralizing properties of free radicals, being able to interact with superoxide, hydroxyl and free oxygen ions, preventing the inflammatory processes, carcinogens, and other processes that accelerate photoaging in the skin. Current research focuses on the search for stable compounds of ascorbic acid and new alternatives for administration in the dermis. Unlike plants and most animals, humans do not have the ability to synthesize our own ascorbic acid due to the deficiency of the enzyme L-gulono-gamma-lactone oxidase, which catalyzes the passage terminal in the ascorbic acid biosynthesis. To deal with this situation, humans obtain this vitamin from the diet and/or vitamin supplements, thus preventing the development of diseases and achieving general well-being. Ascorbic acid is involved in important metabolic functions and is vital for the growth and maintenance of healthy bones, teeth, gums, ligaments, and blood vessels. Ascorbic acid is a very unstable vitamin and is easily oxidized in aqueous solutions and cosmetic formulations. Ascorbic acid is extensively used as an ingredient in anti-aging cosmetic products, as sodium ascorbate or ascorbyl palmitate. This review discusses and describes the potential roles for ascorbic acid in skin health and their clinical applications (antioxidative, photoprotective, anti-aging, and anti-pigmentary effects) of topical ascorbic acid on the skin and main mechanisms of action. Considering the instability and difficulty in administering ascorbic acid, we also discuss the importance of several factors involved in the formulation and stabilization of their topical preparations in this review.
\end{abstract}

Keywords: ascorbic acid; vitamin C; photoprotection; antioxidant; topical

\section{Introduction}

Ascorbic acid (vitamin C, Figure 1) is the most plentiful and most typically water-soluble nonenzymic antioxidant in human tissue [1,2]. A high percentage of plants and animals synthesize this vitamin in vivo from glucose. However, in humans and some other vertebrates, ascorbic acid cannot be synthesized due to the lack of the enzyme L-glucono-gamma lactone oxidase and must be obtained from the diet $[3,4]$.

The chemically active form of the ascorbic acid used in medical practice is L-ascorbic acid (LAA).

The chemical structure of ascorbic acid determines its physical and chemical properties. It is a weak, water-soluble, unstable organic acid which can be easily oxidized or destroyed by light, aerobic conditions (oxygen), high temperatures, alkali, copper, and heavy metals. Vitamins are organic 
substances that maintain metabolic functioning and are highly sensitive to different physical and chemical agents. From the study of the chemical structure of ascorbic acid, we can determine some of its physicochemical properties, which is a weak organic acid, water-soluble and easily degraded by changes in temperature, exposure to sunlight, and oxygen concentration $[5,6]$.

The absorption of ascorbic acid in the intestine is limited by an active transport mechanism. Therefore, a finite amount of the drug is absorbed despite the high oral dose [3,7]. The bioavailability of ascorbic acid in the skin is inadequate when administered orally. Consequently, oral route cannot actually provide a source of ascorbic acid to peripheral structures as skin. The only route that can provide an ascorbic acid source for skin is the topical or local routes, demonstrating that the usage of local application promotes the surgical healing and better tissue reconstruction. Consequently, the oral route of administration does not provide a source of ascorbic acid to structures such as the skin. Instead, topical or local routes can provide a source of ascorbic acid, demonstrating that local application promotes surgical healing and better tissue reconstruction $[1,3,7]$.

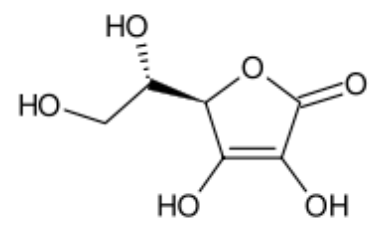

Figure 1. Chemical structure of ascorbic acid.

The main function of the skin is to act as a barrier against external agents, and its unique structure demonstrates this. The skin, a constantly changing dynamic organ, is composed of two main layers. First is the epidermis, which is the outermost, highly cellular layer that protects us against toxins, bacteria, and fluid loss. Second is the dermis, which is a deeper layer that ensures strength and elasticity and provides nutritional support to the epidermis $[8,9]$. This organ is vital for our health and well-being. In addition to acting as the body's first defensive line against bacteria and viruses, healthy skin maintains fluid balance and helps regulate body temperature.

Normal skin contains high concentrations of ascorbic acid, with levels comparable to other body tissues and well above plasma concentrations, suggesting an active accumulation of this compound. Ascorbic acid is transported to the cells from the blood vessels present in the dermal layer. There are only a few reports concerning ascorbic acid levels in the skin, and usually they are not concordant. These variations may be due to the difficulty in managing skin tissue, which is very resistant to degradation and solubilization, but may also be due to the location of the skin sample and the age of the donor. Because ascorbic acid is a natural antioxidant soluble in water, it has been used as an ingredient in numerous cosmetic products to protect and rejuvenate the skin. Most of the ascorbic acid in the skin appears to be located in the intracellular compartments, with concentrations likely to be in the millimolar range. Intracellular compartment was the site where the highest concentrations in the millimolar range have been measured [10-12]. The ascorbic acid content in mg per $100 \mathrm{~g}$ fresh weight in skeletal muscle is approximately 4, in the liver between 10 and 16 [11], in the brain between 13 and 15 [12], in the dermis between 3 and 13 [12-14] and in the epidermis between 6 and 64 [12-14].

Furthermore, the skin collaborates in other functions such as antioxidant protection against UV-induced photodamage and collagen synthesis. All of the above serves as a basis to demonstrate the essentials of the use of topical ascorbic acid in dermatological practice.

\section{Mechanism of Action}

Ascorbic acid belongs to the group of enzymatic and non-enzymatic antioxidants that act by protecting the skin of the reactive oxygen species (ROS). Due to its high aqueous solubility, ascorbic acid is available in the aqueous compartments of the cell. Then, after exposure to ultraviolet light, ROS are generated as superoxide ion, peroxide, and singlet oxygen. Ascorbic acid acts to protect the 
skin from oxidative stress by the sequential donation of electrons to neutralize free radicals, since the oxidized forms of ascorbic acid are relatively unreactive.

Repeated exposure to UV light reduces the availability of ascorbic acid in the skin. Ascorbic acid is involved in synthesis, depigmentation and antioxidant activity in the skin.

As an antioxidant, ascorbic acid acts to protect the skin against reactive oxygen species (ROS) generated by exposure to sunlight. In biological systems, it reduces free radicals based on both oxygen and nitrogen, and therefore delays the aging process. Ascorbic acid in skin care formulations is often used in combination with another redox partner, vitamin E, to slow down its oxidative degradation [3-5]. Currently, medicine recognizes that skin flaccidity and other signs of degenerative skin conditions, such as wrinkles and age spots, are mainly due to an oxyradical damage.

\subsection{Photographic Damage/Photoaging/Photoprotection}

UV radiation produces the generation of free radicals that damage ascorbic acid and can effectively interfere with the appearance of reactive species of oxygen induced by UV rays, reacting or suppressing superoxide anion, hydroxyl radical, and singlet oxygen [14-17]. Dunham et al. demonstrated that increases in the amount of ascorbic acid in the diet can reduce UV-induced tumors [18]. Murray et al. treated the volar forearms of 10 volunteers with a $10 \%$ ascorbic acid solution, a concentration that allows the administration of pharmacological levels of ascorbic acid to the skin. After UVB irradiation, sites treated with topical ascorbic acid showed a significant reduction in the minimum dose of erythema and a less intense erythematous response than controls [19]. Darr et al. investigated the effects of topical ascorbic acid on porcine skin. An increase in ascorbic acid levels was observed in the skin by topical application. Furthermore, they found a marked decrease in ascorbic acid levels in the skin after UV exposure. In other studies, human sunburned cells decreased, and improvement occurred after three days of UVB exposure to sites treated with 10\% topical ascorbic acid 15 to 30 minutes before exposure. UVA-mediated phototoxic response was decreased by following this topical ascorbic acid application regimen [20].

Although ascorbic acid has no UV absorption spectra in the UVA (320 to $400 \mathrm{~nm}$ ) or UVB (290 to $320 \mathrm{~nm}$ ) range, topical ascorbic acid is able to exert photoprotection against UVR due to its antioxidant and anti-inflammatory properties.

\subsection{Wound Healing}

Ascorbic acid acts as a cofactor for several enzymes, such as lysyl hydroxylase and prolyl hydroxylase. It is a stabilizing collagen and is fundamental in wound healing. When ascorbic acid is deficient, fibroblasts produce unstable collagen, providing a weak framework for repair, which makes wound healing difficult.

Phillips and Pinnell showed that ascorbic acid counteracted the reduced proliferative capacity of in vivo fibroblasts in older people [21]. Finglas et al. reported lower plasma ascorbic acid concentrations in the elderly (64-74 years) compared to healthy adults (20-64 years) [22]. Ascorbic acid levels are usually low in older patients, which may contribute to slower and more difficult wound healing.

The role of ascorbic acid supplementation in wound healing remains controversial. Levenson and Demetriou found no evidence that wound healing is improved by ascorbic acid supplementation, although critically ill patients may benefit from supplements because their reserves are depleted [23]. When patients have low levels of ascorbic acid, it is usually observed to a slower and more difficult wound healing.

At present, the role of ascorbic acid supplementation in wound healing is still being discussed. In their studies, Levenson and Demetriou found no evidence that wound healing improves with ascorbic acid supplementation, although critically ill patients benefited from the supplements because their stores are depleted [23]. 


\subsection{Anti-Pigmentary}

Ascorbic acid also plays a role as anti-pigmentary agent. It interacts with copper ions at the active site of the tyrosinase enzyme thereby inhibiting the action of the enzyme. Tyrosinase is the main enzyme responsible for converting tyrosine into melanin, thereby decreasing melanin formation [24]. A clinical study examining the effect of a topical formulation containing $25 \%$ ascorbic acid and a chemical penetration enhancer reported a significant decrease in pigmentation caused by melasma after 16 weeks [25].

\section{Topical Formulations of Ascorbic Acid}

The optimal concentration of ascorbic acid depends on its formulation. In most cases, for a product to be biologically important, it needs to have an ascorbic acid concentration greater than eight percent [26]. Studies have shown that a concentration greater than 20 percent does not increase its biological importance and, conversely, may cause some irritation [27].

The optimal concentration of ascorbic acid depends on its formulation. For a product containing ascorbic acid to have the desired effect, it must have an ascorbic acid concentration greater than eight percent [26]. Studies have shown that a concentration greater than 20 percent does not increase its activity, but may cause some irritation [26].

Ascorbic acid is present in many cosmetic formulations. It can be used alone or in combination with other active ingredients. The first ascorbic acid products contained only the active form of ascorbic acid. These formulations often turned yellow due to the formation of dehydroascorbic acid, an oxidant byproduct of ascorbic acid which formed after to an exposition to air.

Because L-ascorbic acid is a hydrophilic, unstable and charged molecule, its penetration into the skin is poor due to the hydrophobic nature of the horny layer. For optimal penetration of the epidermal barrier, aqueous formulations of ascorbic acid must be at a $\mathrm{pH}$ which is below the $\mathrm{pKa}$ (4.2) of ascorbic acid itself. There is a product of L-ascorbic acid currently available to which ferulic acid was added, thus allowing the stabilization of the molecule as a reduction to a $\mathrm{pH}$ lower than 3.5.

High $\mathrm{pH}$ or temperature, the presence of dissolved oxygen, and catalytic amounts of metal ions are other factors that increase the rate of degradation of ascorbic acid $[27,28]$.

Some strategies can be considered to solve the issue, such as encapsulation, low $\mathrm{pH}$, oxygen-impermeable packaging, and the inclusion of electrolytes and other antioxidants [29-31].

For the instability of LAA, the cosmetic industry turned to more stable and easier to formulate derivatives such as ascorbyl 6-palmitate, tetra-isopalmitoyl ascorbate, magnesium ascorbyl phosphate, sodium ascorbyl phosphate, ascorbyl 2-glucoside, ascorbyl 2-phosphate-6-palmitate, and 3-O-ethyl ascorbate.

Within the group of non-saline derivatives of ascorbic acid are ascorbyl 6-palmitate, ascorbyl-2-glucoside, and tetra-isopalmitoyl ascorbate, which, to a greater or lesser extent, demonstrate superior stability and greater ease of formulation. Ascorbyl 2-glucoside is one of the most important L-ascorbic acid derivatives because of its resistance to reduction and oxidation. It is also easily degraded by a-glucosidase to release $\mathrm{L}$-ascorbic acid and glucose.

The synthetic ester of ascorbic acid, the ascorbyl 6-palmitate, is a compound stable in cosmetic formulas at neutral $\mathrm{pH}$. As a result of the hydrolysis of ascorbyl palmitate, ascorbic acid and palmitic acid are obtained. It was observed that burns caused by UV radiation in patients who applied ascorbyl palmitate obtained a reduced redness by $50 \%$, suggesting that the derivative acts as an antioxidant and anti-inflammatory agent [32].

Ascorbyl 2-phosphates are usually formulated as their sodium and magnesium salts. These are stable in solution at $\mathrm{pH} 7.0$ and their effectiveness depends upon their conversion in vivo to ascorbic acid.

Magnesium-L-ascorbyl-2-phosphate, the most stable and preferred ascorbyl ester, generates protection against UVB radiation induced by lipid peroxidation in hairless mice. In vitro studies show evidence that magnesium ascorbyl phosphate penetrates the epidermis and forms ascorbic acid through the dephosphorylation of the cell membrane [33,34]. Kameyama et al. demonstrated a clinical 
improvement in an in vivo study in melasma and senile freckles when a $10 \%$ topical formulation of ascorbyl phosphate and magnesium was applied [35]. It is also a free radical scavenger that is photoprotective and increases collagen production under laboratory test conditions. Besides being a free radical scavenger, it is a photoprotective agent that allows to increase the levels of collagen production in laboratory assays.

Ascorbyl 2-phosphate 6-palmitate can penetrate through the skin and can be converted to ascorbic acid after delivery, showing skin absorption limited by topical application.

The lipophilicity of 3-O-ethyl ascorbate appears to be greater than for ascorbyl 2-glucoside. This is due to chain-breaking agents with markedly affinity for biomembranes [36,37]. Due to these lipophilic and hydrophilic properties of the molecule, it is more easily absorbed through the skin than other ascorbic acid derivatives. It is used as skin-conditioning agent, but is also considered to have whitening and antioxidant properties, which are particularly interesting for anti-aging cosmetics.

\section{Safety}

Ascorbic acid is safe at high levels of usage for long periods of time, in part due to its solubility in water.

No adverse effects have been observed in any of the well-controlled studies reviewed that indicated daily intakes of more than 100 times the U.S. recommended daily amount of vitamin. Any excess consumption tends to excrete from the body in the urine [38]. This is the reason why concentrations of ascorbic acid and other water-soluble vitamins can rarely accumulate to toxic levels.

Some research suggests that ascorbic acid intake between $1000 \mathrm{mg}$ and $1500 \mathrm{mg}$ per day may impact the body negatively, such as by causing gastric pain, diarrhea, and flatulence. However, these effects have not been demonstrated in laboratory tests and the toxicity risks of ascorbic acid with high levels of use appear to be relatively small compared to the positive health benefits associated with the use of ascorbic acid.

Ascorbic acid and its derivatives, such as 3-O-ethyl ascorbate or tetra-isopalmitoyl ascorbate, are used as anti-aging cosmetic products. There are few cases reported in the literature regarding contact dermatitis caused by ascorbic acid derivatives in cosmetic topical formulations. Belhadjali et al. reported a case of allergic contact dermatitis caused by ascorbic acid used in an anti-aging topical formulation while the oral ascorbic acid formulation was well tolerated [39]. Allergic contact dermatitis caused by ascorbyl tetraisopalmitate in topical formulations used to treat atopic dermatitis and in an anti-aging lotion has also been reported [40,41]. Allergic contact dermatitis related to 3-O-ethyl ascorbate in cosmetics has already been described in three previous cases in skin-whitening and skin-lightening cosmetics [42-44].

\section{Future Developments}

Due to the inherent hydrophilicity of ascorbic acid, there is great interest in finding effective transepidermal delivery methods for the stable active compound. If antioxidants could be administered at high concentration through the stratum corneum barrier, then a dermal reservoir of protective antioxidant could be increased, resulting in an improved photoprotection. The use of stable lipophilic esterified derivatives of ascorbic acid is being studied with this objective [3]. At the same time, different studies are being carried out to investigate multilayered microspheres, nanoparticles, and microemulsions for graduated topical administration. Vitamin $C$ and vitamin $E$ have been tested in the same multilayer emulsions together. Electroporation and iontophoresis have also been used to improve the penetration of ascorbic acid through dermis [45,46]. Ascorbic acid is a good preparation agent and a postoperative agent for the prevention of erythema after laser resurfacing. Smoking-related skin aging is another area in which the effectiveness of ascorbic acid is being explored, with smokers found to have low levels of ascorbic acid in the dermis, similar to those of UV-damaged skin. Another very useful application of ascorbic acid can be stretch marks, where a study has shown 
that daily application of ascorbic acid combined with $20 \%$ glycolic acid for three months can significantly improve striae [47].

\section{Conclusions}

The role of ascorbic acid to promote healthy skin has been under discussion since its discovery in the 1930s as a treatment for scurvy, a disease that is caused by deficiency of ascorbic acid. From there arises the fundamental role of this vitamin in skin health. The first function attributed to ascorbic acid was to cofactor collagen hydroxylases, but understanding the importance of this function for the maintenance of skin health throughout human life led to the hypothetical health benefit of ascorbic acid to skin health. In addition, the antioxidant activity of ascorbic acid made it a candidate for protection against UV irradiation. These recognized activities have driven most of the research on the role of ascorbic acid and skin health to date.

Ascorbic acid has many important biochemical functions. From numerous investigations on the role of ascorbic acid in skin health we can summarize the following:

(1) Administration of ascorbic acid to the skin through topical application remains a challenge due to its instability and aqueous solubility. Although some human studies have suggested a beneficial effect with respect to UV protection, the most effective formulations contain vitamins $C$ and $E$ in addition to a distribution vehicle.

(2) The intake of vegetables and fruits is beneficially related to good skin health. Although the active component of fruits and vegetables responsible for this benefit has not been identified since it is probably a multifactorial effect, it was demonstrated that the presence of ascorbic acid is closely related to the intake of these foods.

(3) Although skin changes are difficult to follow (some research incorporates objective measurements of the depth of wrinkles), it has been shown that the signs of aging in human skin can be improved by ascorbic acid, and administering ascorbic acid to the skin markedly aids wound healing by minimizing the appearance of elevated scars.

Clinical studies on the efficacy of topical ascorbic acid formulations remain limited, and the challenge is to find the most stable and permeable formulation to achieve optimal results.

Author Contributions: All authors have contributed substantially to the reported work.

Funding: This research received no external funding.

Acknowledgments: Thanks are due to the National University of Córdoba, National University of Villa María and National Council of Scientific and Technical Research (CONICET).

Conflicts of Interest: The authors declare no conflict of interest.

\section{References}

1. Traikovich, S.S. Use of Topical Ascorbic acid and its effects on Photo damaged skin topography. Arch. Otorhinol. Head Neck Surg. 1999, 125, 1091-1098. [CrossRef] [PubMed]

2. Colven, R.M.; Pinnell, S.R. Topical vitamin C in anging. Clin. Dermatol. 1996, 14, 227-234. [CrossRef]

3. Telang, P.S. Vitamin C in dermatology. Indian Dermatol. Online J. 2013, 4, 143-146. [CrossRef] [PubMed]

4. Al-Niaimi, F.; Chiang, N.Y.Z. Topical Vitamin C and the Skin: Mechanisms of Action and Clinical Applications. J. Clin. Aesthet. Dermatol. 2017, 10, 14-17.

5. Pielesz, A.; Biniaś, D.; Bobiński, R.; Sarna, E.; Paluch, J.; Waksmańska, W. The role of topically applied 1-ascorbic acid in ex-vivo examination of burn-injured human skin. Spectrochim. Acta A Mol. Biomol. Spectrosc. 2017, 185, 279-285. [CrossRef]

6. Janda, K.; Kasprzak, M.; Wolska, J. Vitamin C-structure, properties, occurrence and functions. Pomeranian J. Life Sci. 2015, 61, 419-425.

7. Talakoub, L.; Neuhaus, I.M.; Yu, S.S. Cosmeceuticals. In Cosmetic Dermatology; Alam, M., Gladstone, H.B., Tung, R.C., Eds.; Saunders Elsevier: New York, NY, USA, 2009; pp. 13-14. 
8. Pullar, J.M.; Carr, A.C.; Vissers, M.C.M. The Roles of Vitamin C in Skin Health. Nutrients 2017, 9, 866.

9. Wickett, R.R.; Visscher, M.O. Structure and function of the epidermal barrier. Am. J. Infect. Control. 2006, 34, S98-S110. [CrossRef]

10. Shindo, Y.; Witt, E.; Han, D.; Epstein, W.; Packer, L. Enzymic and non-enzymic antioxidants in epidermis and dermis of human skin. J. Investig. Dermatol. 1994, 102, 122-124. [CrossRef]

11. McArdle, F.; Rhodes, L.E.; Parslew, R.; Jack, C.I.; Friedmann, P.S.; Jackson, M.J. UVR-induced oxidative stress in human skin in vivo: Effects of oral vitamin C supplementation. Free Radic. Biol. Med. 2002, 33, 1355-1362. [CrossRef]

12. Schaus, R. The vitamin C content of human pituitary, cerebral cortex, heart, and skeletal muscle and its relation to age. Am. J. Clin. Nutr. 1957, 5, 39-41. [CrossRef] [PubMed]

13. Kirk, J.E. Vitamins and Hormones; Academic Press: New York, NY, USA, 1962; pp. 83-92.

14. Rhie, G.; Shin, M.H.; Seo, J.Y.; Choi, W.W.; Cho, K.H.; Kim, K.H.; Park, K.C.; Eun, H.C.; Chung, J.H. Agingand photoaging-dependent changes of enzymic and nonenzymic antioxidants in the epidermis and dermis of human skin in vivo. J. Investig. Dermatol. 2001, 117, 1212-1217. [CrossRef] [PubMed]

15. Scarpa, M.; Stevenato, R.; Viglino, P.; Rigo, A. Superoxide ion as active intermediate in the autoxidation of ascorbate by molecular oxygen: effect of superoxide dismutase. J. Biol. Chem. 1983, 258, 6695-6697. [PubMed]

16. Cabelli, D.E.; Bielski, B.H.J. Kinetics and mechanism for the oxidation of ascorbic acid/ascorbate by $\mathrm{HO}_{2} / \mathrm{O}_{2}$ radicals: A pulse radiolysis and stopped flow photolysis study. J. Phys. Chem. 1983, 87, 1805-1812. [CrossRef]

17. Chou, P.T.; Khan, A.U. L-ascorbic acid quenching of singlet delta molecular oxygen in aqueous media: generalized antioxidant property of vitamin C. Biochem. Biophys. Res. Commun. 1983, 115, 932-937. [CrossRef]

18. Dunham, W.B.; Zuckerkandl, E.; Reynolds, R.; Willoughby, R.; Marcuson, R.; Barth, R.; Pauling, L. Effects of intake of L-ascorbic acid on the incidence of dermal neoplasms induced in mice by ultraviolet light. Proc. Natl. Acad. Sci. USA 1982, 79, 7532-7536. [CrossRef]

19. Murray, J.; Darr, D.; Reich, J.; Pinnell, S. Topical vitamin C treatment reduces ultraviolet B radiation-induced erythema in human skin. J. Investig. Dermatol. 1991, 96, 587.

20. Darr, D.; Combs, S.; Dunston, S.; Manning, T.; Pinnell, S.R. Topical vitamin C protects porcine skin from ultraviolet radiation-induced damage. Br. J. Dermatol. 1992, 127, 24753. [CrossRef]

21. Phillips, C.L.; Combs, S.B.; Pinnell, S.R. Effects of ascorbic acid on proliferation and collagen synthesis in relation to the donor age of human dermal fibroblasts. J. Investig. Dermatol. 1994, 103, 228-232. [CrossRef]

22. Finglas, P.M.; Bailey, A.; Walker, A.; Loughridge, J.M.; Wright, A.J.A.; Southon, S. Vitamin C intake and plasma ascorbic acid concentration in adolescents. Br. J. Nutr. 1993, 69, 563-576. [CrossRef]

23. Levenson, S.M.; Demetriou, A.A. Metabolic factors. In Wound Healing Biochemical E Clinical Aspects; Cohen, I.K., Diegelmann, R.F., Lindblad, W.J., Eds.; W.B. Saunders Company: Philadelphia, PA, USA, 1992; pp. 24-273.

24. Ando, H.; Kondoh, H.; Ichihashi, M.; Hearing, V.J. Approaches to identify inhibitors of melanin biosynthesis via the quality control of tyrosinase. J. Investig. Dermatol. 2007, 127, 751-761. [CrossRef] [PubMed]

25. Hwang, S.W.; Oh, D.J.; Lee, D.; Kim, J.W.; Park, S.W. Clinical efficacy of 25\% L-ascorbic acid (C'ensil) in the treatment of melisma. J. Cutan. Med. Surg. 2009, 13, 74-81. [CrossRef] [PubMed]

26. Pinnell, S.R.; Yang, H.; Omar, M.; Monteiro-Riviere, N.; DeBuys, H.V.; Walker, L.C.; Wang, Y.; Levine, M. Topical L-ascorbic acid: percutaneous absorption studies. Dermatol. Surg. 2001, 27, 137-142. [CrossRef] [PubMed]

27. Tsao, C.S.; Young, M. A stabilized ascorbic acid solution. Med. Sci. Res. 1996, 24, 473-475.

28. Ahmad, I.; Sheraz, R.H.; Shaikh, R.H.; Ahmed, S.; Vaid, F.H.M. Photostability of ascorbic acid in aqueous and organic solvents. J. Pharm. Res. 2010, 3, 1237-1239.

29. Yang, J.H.; Lee, S.Y.; Han, Y.S.; Park, K.C.; Choy, J.H. Efficient transdermal penetration and improved stability of L-ascobic acid. Bull. Korean Chem. Soc. 2003, 24, 499-503.

30. Lee, J.S.; Kim, J.W.; Han, S.H.; Chang, I.S.; Kang, H.H.; Lee, O.S.; Oh, S.G.; Suh, K.D. The stabilization of L-ascorbic acid in aqueous solution and water-in-oil-in-water double emulsion by controlling $\mathrm{pH}$ and electrolyte concentration. J. Cosmetic Sci. 2004, 55, 1-12. [CrossRef]

31. Sheraz, M.A.; Ahmed, S.; Ahmad, I.; Vaid, F.H.M.; Iqbal, K. Formulation and stability of ascorbic acid in topical preparations. Sys. Rev. Pharm. 2011, 2, 86-90. [CrossRef] 
32. Perricone, N.V. The photoprotective and anti-inflammatory effects of topical ascorbyl palmitate. J. Ger. Dermatol. 1993, 1, 5-10.

33. Kobayashi, S.; Takehana, M.; Itoh, S.; Ogata, E. Protective effect of magnesium-L-ascorbyl-2-phosphate against skin damage induced by UVB irradiation. Potochem. Photobiol. 1996, 64, 224-228. [CrossRef]

34. Hata, R.; Senno, H. L-ascorbic acid 2-phosphate stimulates collage accumulation, cell proliferation, and formation of a three-dimensional tissuelike substance by skin fibroblast. J. Cell. Physiol. 1989, 138, 8-16. [CrossRef] [PubMed]

35. Kameyama, K.; Sakai, C.; Kondoh, S.; Yonemoto, K.; Nishiyama, S.; Tagawa, M.; Murata, T.; Ohnuma, T.; Quigley, J.; Dorsky, A.; et al. Inhibitory effect of magnesium-L-ascorbyl-2-phosphate (VC-PMG) on melanogenesis in vitro and in vivo. J. Am. Acad. Dermatol. 1996, 34, 29-33. [CrossRef]

36. Hsiao, C.Y.; Huang, C.H.; Hu, S.; Ko, Y.S.; Sung, H.C.; Huang, S.Y. Skin pretreatment with lasers promotes the transdermal delivery of vitamin C derivatives. Lasers Med. Sci. 2011, 26, 369-376. [CrossRef] [PubMed]

37. Nihro, Y.; Miyataka, H.; Sudo, T.; Matsumoto, H.; Satoh, T. 3-O-Alkylascorbic acids as free-radical quenchers: synthesis and inhibitory effect of lipid peroxidation. J. Med. Chem. 1991, 34, 2152-2157. [CrossRef]

38. Bendich, A.; Langseth, L. Safety of vitamin A. Am. J. Clin. Nutr. 1989, 49, 358-371. [CrossRef]

39. Belhadjali, H.; Giordano-Labadie, F.; Bazex, J. Contact dermatitis from vitamin C in a cosmetic anti-aging cream. Contact Dermatitis. 2001, 45, 317. [CrossRef]

40. Assier, H.; Wolkenstein, P.; Grille, C.; Chosidow, O. Contact dermatitis caused by ascorbyl tetraisopalmitate in a cream used for the management of atopic dermatitis. Contact Dermatitis. 2014, 71, 60-61. [CrossRef]

41. Swinnen, I.; Goossens, A. Allergic contact dermatitis caused by ascorbyl tetraisopalmitate. Contact Dermatitis. 2011, 64, 241-242. [CrossRef]

42. Victoria-Martínez, A.; Mercader-García, P. Allergic contact dermatitis to 3-o-ethyl-L-ascorbic acid in skin-lightening cosmetics. Dermatitis 2017, 28, 89. [CrossRef]

43. Yagami, A.; Suzuki, K.; Morita, Y.; Iwata, Y.; Sano, A.; Matsunaga, K. Allergic contact dermatitis caused by 3-o-ethyl-1-ascorbic acid (vitamin C ethyl). Contact Dermatitis. 2014, 70, 376-377. [CrossRef]

44. Numata, T.; Kobayashi, Y.; Ito, T.; Harada, K.; Tsuboi, R.; Okubo, Y. Two cases of allergic contact dermatitis due to skin-whitening cosmetics. Allergol. Int. 2015, 64, 194-195. [CrossRef] [PubMed]

45. Lee, W.R.; Shen, S.C.; Kuo-hsien, W.; Hu, C.H.; Fang, J.Y. Lasers and microdermabrasion enhance and control topical delivery of vitamin C. J. Investig. Dermatol. 2003, 121, 1118-1125. [CrossRef] [PubMed]

46. Ebihara, M.; Akiyama, M.; Ohnishi, Y.; Tajima, S.; Komata, K.; Mitsui, Y. Iontophoresis promotes percutaneous absorption of L-ascorbic acid in rat skin. J. Dermat. Sci. 2003, 32, 217-222. [CrossRef]

47. Ash, K.; Lord, J.; Zukowski, M.; McDaniel, D.H. Comparison of topical therapy for striae alba (20\% glycolic acid/0.05\% tretinoin versus $20 \%$ glycolic acid/10\% L-ascorbic acid). Dermatol. Surg. 1998, 24, 849-856. [CrossRef]

(C) 2019 by the authors. Licensee MDPI, Basel, Switzerland. This article is an open access article distributed under the terms and conditions of the Creative Commons Attribution (CC BY) license (http://creativecommons.org/licenses/by/4.0/). 